\title{
Effect of corticosteroid injections versus physiotherapy on pain, shoulder range of motion and shoulder function in patients with subacromial impingement syndrome: A systematic review and meta-analysis
}

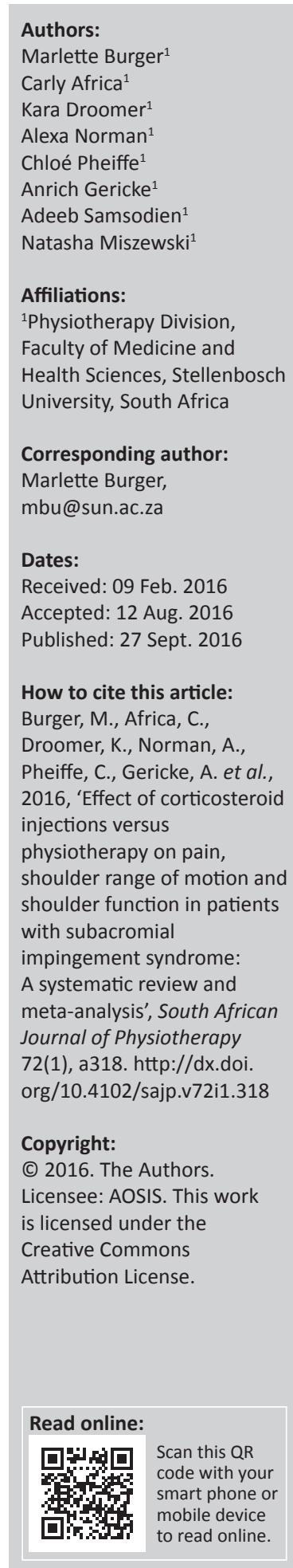

Background: Subacromial impingement syndrome (SIS) is one of the most common causes of shoulder pain. Limited research has been conducted into the efficacy of corticosteroid injections (CSIs) compared to physiotherapy in the management of SIS.

Objective: To critically appraise and establish the best available evidence for the effectiveness of CSI in comparison with physiotherapy for the management of pain, shoulder range of motion (ROM) and shoulder function in patients with SIS.

Methodology: Seven databases were searched from inception to February 2016, namely PubMed, Science Direct, EBSCO Host: SPORTDiscus, EBSCO Host: CINAHL, Cochrane, Scopus and PEDro. The main search terms were shoulder impingement syndrome and/or subacromial impingement syndrome, corticosteroid injections and/or steroid injections, physical therapy and/or physiotherapy. Only randomised controlled trials (RCTs) were considered for inclusion. The articles were appraised according to the PEDro scale. The Revman $^{\odot}$ Review Manager Software was used to combine the results of shoulder function and the data were illustrated in forest plots.

Results: The PEDro scores of the three RCTs that qualified for this review ranged from 7 to $8 / 10$. There is Level II evidence suggesting that besides a significant improvement in shoulder function in favour of CSI at 6-7 weeks follow-up $(p<0.0001)$, no evidence was found for the superiority of CSIs compared with physiotherapy for pain, ROM and shoulder function in the short- (1-3 months), mid- (6 months) and long term (12 months).

Conclusion: In patients with SIS only a short term significant improvement in shoulder function was found in favour of CSIs.

\section{Introduction}

Subacromial impingement syndrome (SIS) is one of the most common causes of shoulder pain and is defined as a narrowing of the subacromial space with subsequent impingement of the bursa, long head of the biceps tendon, the rotator cuff tendons and the coracoacromial ligament (Umer, Qadir \& Azam 2012). SIS can present in more than one form and although impingement syndrome represents the supraspinatus muscle impinging beneath the acromion, it does not fully describe the extent of the underlying shoulder pathology (Cummins, Sasso \& Nicholson 2009). SIS may range from subacromial bursitis and/or inflammation in the rotator cuff tendons to degeneration of the bursa or rotator cuff tendons to full-thickness rotator cuff tendon tears or more serious degenerative joint disease within the shoulder girdle (Harrison \& Flatow 2011; Michener, McClure \& Karduna 2003). The consequences of SIS include moderate to severe shoulder pain that is worsened by movement. This condition often results in functional limitation in flexion and abduction range and may cause loss of function and disability (Akgün, Birtane \& Akarırmak 2004; Crawshaw et al. 2010; Michener et al. 2003).

There is a wide variety of conservative treatments for SIS ranging from different physiotherapy modalities such as joint mobilisation techniques and strengthening exercises, adaptations of daily activities, non-steroidal anti-inflammatory drugs (NSAIDs) as well as steroid injections (Dorrestijn et al. 2009). Subacromial corticosteroid injection (CSI) is a popular SIS treatment method amongst orthopaedists, rheumatologists and general practitioners (Rhon, Boyles \& 
Cleland 2014). This method is regarded as an inexpensive and effective way to both diagnose and treat symptomatic rotator cuff disease and SIS (Gruson, Ruchelsman \& Zuckerman 2008). Therapeutic effects of CSI on pain, inflammation and range of motion (ROM) have mostly been observed as being limited to a short-term effect (Akgün et al. 2004). However, more recent systematic reviews found limited evidence on the effectiveness of CSIs for SIS compared with placebo injections (Dorrestijn et al. 2009; van der Sande et al. 2013).

Physiotherapy treatment techniques for SIS focuses on reducing pain, reversing abnormal muscle imbalances and increasing strength, promoting healing as well as increasing pain-free shoulder motion (Michener, Walsworth \& Burnet 2004). Physiotherapy techniques used to reduce pain and improve active and passive ROM include joint mobilisation techniques to improve motion at the glenohumeral joint as well as the cervical and upper thoracic spine, pendulum exercises as well as strengthening exercises and soft-tissue mobilisation and stretches (Crawshaw et al. 2010; Michener et al. 2004; Rhon et al. 2014). Reversing abnormal rotator cuff muscle and shoulder stabiliser imbalances plays an important role in the physiotherapy management of SIS. A good balance between the stabilisers and the movers around the shoulder increases patient-reported function and helps to reduce pain (Hanratty et al. 2012).

No systematic review has been previously conducted to determine the effect of CSIs compared with physiotherapy in the management of patients with SIS. The purpose of this systematic review was thus to determine the best short-term (1-3 months); medium-term (6 months) and long-term (12 months) approach for the management of SIS by systematically identifying, collating and analysing the current available evidence on the effectiveness of CSIs versus physiotherapy in the treatment of pain, shoulder ROM and shoulder function.

\section{Methodology}

\section{Search strategy}

A total of seven electronic databases, available through Stellenbosch University Library, were searched, namely Pubmed, Science Direct, EBSCO Host: SPORTDiscus, EBSCO Host: CINAHL, Cochrane, Scopus and PEDro. The key search terms used were shoulder impingement syndrome, corticosteroid injections, physical therapy, physiotherapy, steroid injections and subacromial impingement syndrome. Each database received an individual search strategy according to its function. Each database was searched independently by two investigators. Based on the inclusion and exclusion criteria below, investigators independently reviewed the titles, abstracts and full-text articles retrieved in the initial search. The researchers compared the eligible articles selected for inclusion, and disagreements for accepting full-text articles were discussed until consensus was achieved.

\section{Study inclusion and exclusion criteria}

The following inclusion and exclusion criteria were applied:

\section{Type of studies}

Only randomised controlled trials (RCTs) published in English from inception of the databases until February 2016 were eligible for inclusion in this review.

\section{Type of participants}

Study participants could include adults ( $\geq 18$ years), male and/ or females, with primary symptoms of moderate or severe unilateral shoulder pain that was made worse with movement and had a non-capsular pattern of restriction. Tests confirming SIS could include a positive Neer or Hawkins-Kennedy impingement test (Petty 2011). RCTs were excluded if they recruited participants who had a history of previous shoulder injuries, for example, previous shoulder dislocations, rotator cuff ruptures or scapula and/or humeral head/neck fractures, adhesive capsulitis, glenohumeral arthritis or previous shoulder surgery.

\section{Types of interventions}

CSIs including, but not limited to, injections at the midpoint of the acromion as well as in the subacromial space of the symptomatic shoulder.

\section{Types of comparisons}

Physiotherapy management including, but not confined to, manual stretches, contract-relax techniques, strengthening exercises directed to the shoulder girdle or thoracic or cervical spine, electrotherapy modalities and home advice regarding management and precautions. Physiotherapy management had to include a combination of passive and active joint and soft-tissue mobilisation techniques.

\section{Type of outcomes}

RCTs had to assess at least one the following three clinical outcomes, namely pain, ROM and shoulder function.

\section{Evidence hierarchy and methodological appraisal}

According to the National Health and Medical Research Council (NHMRC) Hierarchy of Evidence (Merlin, Weston \& Tooher 2009), a well conducted RCT, as Level II evidence, is appropriate for the purpose of answering an intervention question in a systematic review. The PEDro scale was used to determine the methodological quality and potential sources of bias of the included studies. The PEDro scale is a valid measure of the methodological quality of clinical trials and is widely used in physiotherapy research (de Morton 2009). Each article was allocated to two researchers who individually appraised the article using the PEDro scale. The researchers compared their results and when a discrepancy occurred, a third researcher was consulted. If agreement was not reached at this point, a group discussion between all eight researchers was held to resolve the matter. 


\section{Data extraction and analysis method}

The data were extracted and captured on a Microsoft Excel spreadsheet by one investigator to ensure continuity. The information was cross-checked by the rest of the seven research team members. Mutual consensus amongst the group was ensured after a discussion of the complete data extraction. All data were tabulated into the following categories: citation, type of study, patients (including number of patients and ages), type of intervention, comparisons, outcome measures (including measurement tools, validity and reliability), continuous data (intervention and comparison group), clinical status and implication. The Revman $^{\odot}$ Review Manager Software, which summarises all the statistics in the form of a meta-analysis (RevMan ${ }^{\odot}$ Information Management System 2008), was used to combine the results of shoulder function for two of the included articles and the data were illustrated with forest plots. The outcomes for continues data [mean and standard deviation (SD)] were expressed as weighted mean differences (WMD). Heterogeneity amongst the studies was assessed by the $I^{2}$ statistic. Studies are regarded as homogeneous if $I^{2} \leq 25 \%$, and if $I^{2} \geq 75 \%$, the heterogeneity amongst the studies is considered high (Ried 2006). Statistical pooling for pain and ROM was rendered inappropriate owing to heterogeneity amongst reporting of results and were subsequently summarised in a narrative form and illustrated in tables.

\section{Ethical considerations}

We conducted secondary research, thus ethical approval was not required for this review.

\section{Results}

\section{Search results}

The results of the search strategy are presented in a flow chart (see Figure 1). A total of 1646 initial titles were found. Fourteen full-text articles were assessed according to the inclusion and exclusion criteria and of these, three articles (Hay et al. 2003; Rhon et al. 2014; van der Windt et al. 1998) were considered eligible for this systematic review. Reasons for excluding articles were the following: intervention therapy included CSIs as well as physiotherapy (e.g. manual therapy and/or electrotherapy); participants with a history of previous shoulder injuries were included; and comparison therapy did not include a combination of passive and active joint and soft-tissue mobilisation techniques.

\section{Evidence hierarchy and methodological appraisal}

According to the Hierarchy of Evidence set forth by the NHMRC (2005), the three included articles (Hay et al. 2003; Rhon et al. 2014; van der Windt et al. 1998) were classified as Level II. The methodological quality of the three included articles, according to the PEDro scale, ranged between $7 / 10$ and $8 / 10$, with an average score of $7.3 / 10$ (Table 1 ).
The assessors were not blinded in van der Windt et al. (1998). Because of the nature of the included articles, it was not possible to blind the therapists or the participants.

\section{Description of study sample and interventions}

The summary of the sample descriptions from each study can be found in Table 1. The total sample captured in the three studies was 452. Rhon et al. (2014) included slightly younger participants, while the minimum age across the studies was 18 years and the maximum was 65 years. The three studies were conducted in developed countries. Variation was found in the physiotherapeutic interventions across the three studies (Table 1). All three studies included a baseline of exercise therapy and manual therapy. Hay et al. (2003) included ultrasound, van der Windt et al. (1998) also made use of electrotherapy but specifically excluded ultrasound and added the use of ice and hot packs for pain relief, while Rhon et al. (2014) only made use of manual therapy and exercise. The duration of the physiotherapy intervention was well documented in all three studies. The chemical composition of the corticosteroids in van der Windt et al. (1998) and Rhon et al. (2014) were exactly the same (40 mg triamcinolone acetonide), whereas in Hay et al. (2003) $40 \mathrm{mg}$ methylprednisolone mixed with $4 \% 1 \mathrm{ml}$ lidocaine was used. The site of the CSIs also differed across the three studies. The number of CSIs was specified in van der Windt et al. (1998) and Rhon et al. (2014) but not in Hay et al. (2003).

\section{Description of outcome measures and assessment times}

The outcome measures used in the three articles are summarised in Table 2. Rhon et al. (2014) and van der Windt et al. (1998) conducted a long-term follow-up (52 weeks) assessment, while Hay et al. (2003) conducted the final assessment at 26 weeks.

\section{The effect of corticosteroid injections versus physiotherapy}

The effect of CSIs versus physiotherapy in the treatment of SIS is shown in Tables 3-7 under the following subheadings: pain, shoulder ROM and shoulder function.

\section{Pain}

van der Windt et al. (1998) assessed pain using the Visual Analogue Scale (VAS) (0-100 mm) and the mean change from baseline at 3- to 4-, 6- to 7-, 13-, 26- and 52-week intervals was recorded and tabulated. A statistically significant difference in favour of the CSI group was recorded at 3-4, 6-7, 13 and 52 weeks (Table 3). Rhon et al. (2014) assessed pain using the Numeric Pain Rating scale and found no statistical difference between CSI and physiotherapy groups at the different time intervals (see Table 3).

Hay et al. (2003) made use of the VAS (0-100 mm) to measure the level of pain during the day and night at 6 weeks and 


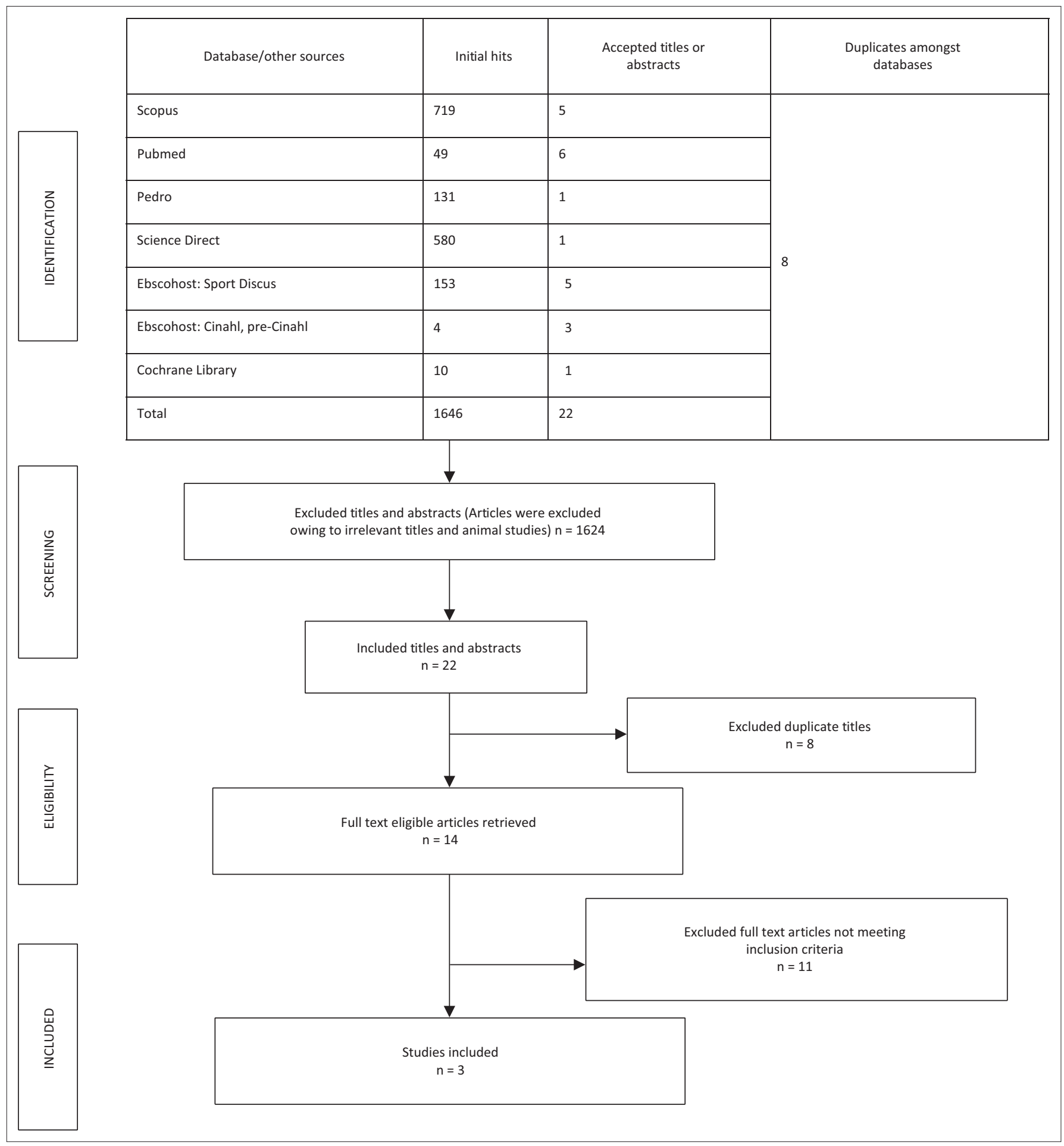

Source: Authors' own work

FIGURE 1: Search results.

6 months (Table 4). The data show that while both the CSI and physiotherapy had a positive effect in decreasing pain, neither had a statistically greater effect $(p>0.05)$.

\section{Shoulder range of motion}

Table 5 shows the mean (SD) improvement in shoulder external rotation and abduction as reported in van der Windt et al. (1998). The effect of CSIs on the range of external shoulder rotation was significantly greater than that of physiotherapy at 3-4, 6-7 and 26 weeks $(p=0.002)$. There were no significant differences between the groups for shoulder abduction at the different time points of measurement $(p=0.065)$.

Hay et al. (2003) measured active abduction and active and passive external shoulder ROM and recorded the percentage of patients not reaching 180 degrees of shoulder abduction and if they had a restriction of $>50 \%$ of external rotation compared with the non-involved arm (Table 6). Both 
TABLE 1: Study sample descriptions.

\begin{tabular}{|c|c|c|c|c|}
\hline Criteria & & Hay et al. (2003) & van der Windt et al. (1998) & Rhon et al. (2014) \\
\hline \multirow[t]{2}{*}{ Sample size } & Corticosteroid injections & 104 & 53 & 73 \\
\hline & Physiotherapy & 103 & 56 & 63 \\
\hline \multirow[t]{2}{*}{ Gender } & Corticosteroid injections & $\begin{array}{l}\text { Male }=42 \\
\text { Female }=44\end{array}$ & $\begin{array}{l}\text { Male }=47 \\
\text { Female }=25\end{array}$ & $\begin{array}{l}\text { Male }=38 \\
\text { Female }=35\end{array}$ \\
\hline & Physiotherapy & $\begin{array}{l}\text { Male }=51 \\
\text { Female }=53\end{array}$ & $\begin{array}{l}\text { Male }=59 \\
\text { Female }=33\end{array}$ & $\begin{array}{l}\text { Male }=29 \\
\text { Female }=34\end{array}$ \\
\hline Age (in years) & Corticosteroid injections & Mean (SD): $57.6 \pm 14$ & Mean (SD): $57.3 \pm 10.2$ & Mean (SD): $42 \pm 12$ \\
\hline PEDro scores & & $8 / 10$ & $7 / 10$ & $7 / 10$ \\
\hline Country & & United Kingdom & The Netherlands & United States \\
\hline \multirow[t]{3}{*}{$\begin{array}{l}\text { Physiotherapy } \\
\text { intervention group }\end{array}$} & Type of treatment & $\begin{array}{l}\text { Advice and instruction on pain relief, } \\
\text { active shoulder exercises, home } \\
\text { programme, manual therapy and } \\
\text { ultrasound. }\end{array}$ & $\begin{array}{l}\text { Passive joint mobilisation, exercise } \\
\text { treatment, ice, hot packs, } \\
\text { electrotherapy. Did not specify } \\
\text { electrotherapy modalities used but } \\
\text { stated that they excluded ultrasound. }\end{array}$ & $\begin{array}{l}\text { Joint and soft-tissue mobilisation, } \\
\text { manual stretches, contract-relax } \\
\text { techniques and reinforcing } \\
\text { exercises aimed at the shoulder } \\
\text { girdle or thoracic or cervical spine. }\end{array}$ \\
\hline & Duration of treatment & $\begin{array}{l}\text { 20-minute individual physiotherapy } \\
\text { sessions for } 6 \text { weeks. }\end{array}$ & $\begin{array}{l}30 \text {-minute individual sessions for } \\
6 \text { weeks. }\end{array}$ & Twice a week for 3 weeks. \\
\hline & $\begin{array}{l}\text { Other treatment prescribed if } \\
\text { clinically indicated during and } \\
\text { after the trial }\end{array}$ & $\begin{array}{l}\text { At the end of the trial period, } 29 \\
\text { participants of the physiotherapy group } \\
\text { received steroid injections, } 5 \text { received a } \\
\text { further course of physiotherapy and } 3 \\
\text { were prescribed analgesics or NSAID's. } \\
\text { Of those participants allocated to the } \\
\text { corticosteroid injection group, } 11 \\
\text { received another injection, } 21 \text { received } \\
\text { physiotherapy and } 9 \text { were prescribed } \\
\text { analgesics or NSAIDs. }\end{array}$ & $\begin{array}{l}\text { Patients were allowed to continue } \\
\text { taking medication for pain if they had } \\
\text { already started before enrolment. Pain } \\
\text { medication was also prescribed during } \\
\text { the course of the trial if pain was } \\
\text { severe. All other interventions were to } \\
\text { be avoided. Did not specify post-trial } \\
\text { treatment. }\end{array}$ & $\begin{array}{l}\text { Patients were discouraged to seek } \\
\text { additional care during the first } \\
\text { month of the study period. Did } \\
\text { not specify port-trial treatment. }\end{array}$ \\
\hline \multirow[t]{2}{*}{$\begin{array}{l}\text { Corticosteroid } \\
\text { injection group }\end{array}$} & Type of corticosteroid injection & $\begin{array}{l}40 \mathrm{mg} \text { methylprednisolone mixed with } \\
4 \% 1 \mathrm{ml} \text { lidocaine into the subacromial } \\
\text { space. Originally they got one injection } \\
\text { and were offered a second one. }\end{array}$ & $\begin{array}{l}\text { Intra-articular injections of } 40 \mathrm{mg} \\
\text { triamcinolone acetonide was given to } \\
\text { patients via the posterior route. } \\
3 \text { Injections were given over a } \\
\text { timeframe of } 6 \text { weeks. }\end{array}$ & $\begin{array}{l}\text { Intra-articular injections of } 40 \mathrm{mg} \\
\text { triamcinolone acetonide was given } \\
\text { to patients via the posterior route. } \\
3 \text { Injections were given, } 1 \text { month } \\
\text { apart, over a 1-year timeframe. }\end{array}$ \\
\hline & $\begin{array}{l}\text { Total number of corticosteroid } \\
\text { injections }\end{array}$ & $\begin{array}{l}\text { Patients were given one injection } \\
\text { initially and offered a second one if } \\
\text { they returned with complaints of pain. }\end{array}$ & $\begin{array}{l}\text { No more than } 3 \text { injections were given } \\
\text { during the } 6 \text { weeks. }\end{array}$ & $\begin{array}{l}\text { A total of } 3 \text { injections spaced } \\
1 \text { month apart over the course of } \\
12 \text { months. }\end{array}$ \\
\hline
\end{tabular}

Source: Authors' own work

SD, standard deviation.

TABLE 2: Outcome measurements used and assessment time intervals.

\begin{tabular}{|c|c|c|c|c|c|c|}
\hline Outcome measures & Baseline & 3-4 weeks & 6-7 weeks & 13 weeks & 26 weeks (6 months) & 52 weeks ( 1 year) \\
\hline SDQ & $\begin{array}{l}\text { van der Windt et al. } \\
\text { (1998)/Hay et al. (2003) }\end{array}$ & $\begin{array}{l}\text { van der Windt } \\
\text { et al. (1998) }\end{array}$ & $\begin{array}{l}\text { van der Windt et al. } \\
\text { (1998)/Hay et al. (2003) }\end{array}$ & $\begin{array}{l}\text { van der Windt } \\
\text { et al. (1998) }\end{array}$ & $\begin{array}{l}\text { van der Windt et al. } \\
\text { (1998)/Hay et al. (2003) }\end{array}$ & $\begin{array}{l}\text { van der Windt } \\
\text { et al. (1998) }\end{array}$ \\
\hline VAS & $\begin{array}{l}\text { van der Windt et al. } \\
\text { (1998)/Hay et al. (2003) }\end{array}$ & $\begin{array}{l}\text { van der Windt } \\
\text { et al. (1998) }\end{array}$ & $\begin{array}{l}\text { van der Windt et al. } \\
\text { (1998)/Hay et al. (2003) }\end{array}$ & $\begin{array}{l}\text { van der Windt } \\
\text { et al. (1998) }\end{array}$ & $\begin{array}{l}\text { van der Windt et al. } \\
\text { (1998)/Hay et al. (2003) }\end{array}$ & $\begin{array}{l}\text { van der Windt } \\
\text { et al. (1998) }\end{array}$ \\
\hline ROM & $\begin{array}{l}\text { van der Windt et al. } \\
\text { (1998)/Hay et al. (2003) }\end{array}$ & $\begin{array}{l}\text { van der Windt } \\
\text { et al. (1998) }\end{array}$ & $\begin{array}{l}\text { van der Windt et al. } \\
\text { (1998)/Hay et al. (2003) }\end{array}$ & $\begin{array}{l}\text { van der Windt } \\
\text { et al. (1998) }\end{array}$ & $\begin{array}{l}\text { van der Windt et al. } \\
\text { (1998)/Hay et al. (2003) }\end{array}$ & $\begin{array}{l}\text { van der Windt } \\
\text { et al. (1998) }\end{array}$ \\
\hline SPADI & Rhon et al. (2014) & Rhon et al. (2014) & - & Rhon et al. (2014) & Rhon et al. (2014) & Rhon et al. (2014) \\
\hline NPRS & Rhon et al. (2014) & Rhon et al. (2014) & - & Rhon et al. (2014) & Rhon et al. (2014) & Rhon et al. (2014) \\
\hline GRC & Rhon et al. (2014) & Rhon et al. (2014) & - & Rhon et al. (2014) & Rhon et al. (2014) & Rhon et al. (2014) \\
\hline
\end{tabular}

Source: Authors' own work

SDQ, shoulder disability questionnaire; VAS, Visual Analogue Scale; ROM, range of motion; SPADI, Shoulder Pain and Disability Index; NPRS, Numerical Pain Rating Scale; GRC, global rating of change.

physiotherapy and CSIs caused an increase in abduction and external rotation but neither had a greater effect $(p>0.05)$. Physiotherapy had a greater initial effect when measured in week 6, but at 6 months the scores for both groups were comparable. With regards to the passive external rotation, physiotherapy appeared to have a greater effect by 6 months reducing the score by $9 \%$ compared with baseline, whereas CSI only reduced the score by $1 \%$.

\section{Shoulder function}

Rhon et al. (2014) assessed the improvement of function using the global rating of change (GRC) scale. The results showed that there was a clinically important improvement in functional ability for both the physiotherapy and CSI groups ( $\geq 3$ points from baseline) at 1-month, 3-month, 6-month and 1-year intervals (Table 7). There were no significant differences between the groups at any of the assessment intervals.

Hay et al. (2003) and van der Windt et al. (1998) made use of the shoulder disability questionnaire (SDQ) to measure shoulder function. The following forest plots (Figures 2 and 3) show the combined effect of physiotherapy versus CSIs in improving shoulder function measured at 6-7 weeks and 26 weeks ( 6 months). The overall combined effect at 6-7 weeks (Figure 2) indicated a significant improvement in shoulder function in favour of the CSI group $(p<0.0001)$. However, at 6 months, the overall combined effect indicated no difference between the groups ( $p=0.84$ ) (Figure 2). At the 52-week (1 year) assessment, van der Windt et al. (1998) found no significant differences between the groups [Mean (95\% CI) difference between groups: 4 (-10 to 17)]. 
TABLE 3: Results for the measurement of pain in van der Windt et al. (1998) and Rhon et al. (2014).

\begin{tabular}{|c|c|c|c|c|c|c|c|c|}
\hline \multirow[t]{2}{*}{ Variables } & \multicolumn{4}{|c|}{ van der Windt et al. (1998) } & \multicolumn{4}{|c|}{ Rhon et al. (2014) } \\
\hline & $\begin{array}{c}\text { CSI mean (SD) } \\
\text { improvement from } \\
\text { baseline }\end{array}$ & $\begin{array}{c}\text { Physiotherapy mean (SD) } \\
\text { improvement from } \\
\text { baseline }\end{array}$ & $\begin{array}{l}\text { Mean }(95 \% \mathrm{Cl}) \\
\text { difference } \\
\text { between groups }\end{array}$ & $p$ & CSI Mean (CI) & $\begin{array}{l}\text { Physiotherapy } \\
\text { Mean (CI) }\end{array}$ & $\begin{array}{l}\text { Difference between } \\
\text { groups Mean }(\mathrm{Cl})\end{array}$ & $\begin{array}{c}p \text {-value mean } \\
\text { difference }\end{array}$ \\
\hline Baseline & - & - & - & - & 3.3 (2.7 to 3.9 ) & 3.8 (3.2 to 4.5$)$ & 0.5 (-1.4 to 0.4$)$ & 0.26 \\
\hline $3-4$ weeks & $32(26)$ & $17(21)$ & 15 (6 to 24$)$ & $<0.05$ & 1.7 (1.1 to 2.4$)$ & 1.6 (1.0 to 2.3 ) & $0.1(-0.8$ to 1.0$)$ & 0.80 \\
\hline $6-7$ weeks & $58(28)$ & $32(29)$ & 26 (15 to 37 ) & $<0.05$ & & & & \\
\hline 13 weeks & $66(28)$ & $47(33)$ & 19 (7 to 31$)$ & $<0.05$ & 2.6 (2.0 to 3.2$)$ & 1.8 (1.1 to 2.5$)$ & $0.8(-0.1$ to 1.8$)$ & 0.077 \\
\hline 52 weeks (1 year) & $70(24)$ & $59(30)$ & 11 (1 to 23 ) & $<0.05$ & 2.5 (1.9 to 3.1$)$ & $2.1(1.5$ to 2.8$)$ & $0.4(-0.5$ to 1.2$)$ & 0.42 \\
\hline
\end{tabular}

Source: Authors' own work

Grey Block van der Windt et al. (1998): did not provide baseline measures as means and standard deviations (SD).

Grey Block Rhon et al. (2014): did not measure pain outcomes at 6-7 weeks.

$\mathrm{CSI}$, corticosteroid injections; SD, standard deviation; $\mathrm{Cl}$, confidence interval.

TABLE 4: Results (median and interquartile range) for the measurement of pain in Hay et al. (2003).

\begin{tabular}{|c|c|c|c|}
\hline Variable & Physiotherapy median (IQR) & CSI median (IQR) & $p$-value difference between groups \\
\hline \multicolumn{4}{|l|}{ Pain during the day } \\
\hline Baseline & $50(40-70)$ & $50(40-60)$ & $>0.05$ \\
\hline $6-7$ weeks & $30(10-40)$ & $30(10-50)$ & $>0.05$ \\
\hline 26 weeks/ 6 months & $10(0-30)$ & $20(0-30)$ & $>0.05$ \\
\hline \multicolumn{4}{|c|}{ Pain during the evening } \\
\hline Baseline & $50(30-70)$ & $50(30-70)$ & $>0.05$ \\
\hline $6-7$ weeks & $20(10-40)$ & $30(0-60)$ & $>0.05$ \\
\hline 26 weeks/ 6 months & $10(0-30)$ & $20(0-40)$ & $>0.05$ \\
\hline
\end{tabular}

Source: Authors' own work

IQR, interquartile range; CSI, corticosteroid injections.

TABLE 5: Results (mean and standard deviation) for the measurement of range of motion in van der Windt et al. (1998).

\begin{tabular}{lccc}
\hline Variable & CSI mean (SD) improvement & Physiotherapy mean (SD) improvement & Mean (95\% Cl) difference between groups \\
\hline External rotation & $6(14)$ & $-3(12)$ & $9(3$ to 14$)$ \\
$3-4$ weeks & $13(16)$ & $-2(14)$ & $15(9$ to 20$)$ \\
$6-7$ weeks & $16(18)$ & $7(21)$ & $9(1$ to 16$)$ \\
26 weeks & & & 0.002 \\
Abduction & $2(12)$ & $-3(13)$ & $5(0$ to 9$)$ \\
$3-4$ weeks & $4(11)$ & $-1(14)$ & $5(0$ to 10$)$ \\
$6-7$ weeks & $9(12)$ & $7(17)$ & $2(-3$ to 8$)$ \\
26 weeks & & & 0.065 \\
\hline
\end{tabular}

Source: Authors' own work

A minus (-) indicates decrease in ROM. SD, standard deviation; CSI, corticosteroid injections; $\mathrm{Cl}$, confidence interval.

TABLE 6: Results for the measurement of range of motion (\%) in Hay et al. (2003).

\begin{tabular}{lrc}
\hline Variable & CSI & Physiotherapy \\
\hline Restricted active abduction (\% yes) & $73 \%$ & $76 \%$ \\
Baseline & $54 \%$ & $40 \%$ \\
$6-7$ weeks & $39 \%$ & $31 \%$ \\
26 weeks/6 months & \\
Restricted active external rotation (\% yes) & $21 \%$ \\
Baseline & $9 \%$ & $8 \%$ \\
$6-7$ weeks & $12 \%$ & $7 \%$ \\
26 weeks/6 months & $8 \%$ & \\
Restricted passive external rotation (\% yes) & $14 \%$ \\
Baseline & $7 \%$ & $7 \%$ \\
$6-7$ weeks & $7 \%$ & $5 \%$ \\
26 weeks/6 months & $6 \%$ & \\
\hline
\end{tabular}

Source: Authors' own work

CSI, corticosteroid injections.

\section{Discussion}

This is the first systematic review on the effectiveness of physiotherapy compared with CSIs in patients with SIS. Our findings suggested that physiotherapy and CSIs both showed improvement in pain, shoulder ROM and shoulder function in the short term (1-3 months), mid-term (6 months) and long term (12 months). Rhon et al. (2014) showed recovery in both groups from baseline up until and including 1 year for pain and function; however, no significant differences were found between the two groups at any time point. Hay et al. (2003) showed no difference between the physiotherapy group and the CSIs group with regard to pain, function and ROM as measured at 6-7 weeks and 6 months. A meta-analysis of the combined short-term effect of shoulder function at 6-7 weeks (Hay et al. 2003; van der Windt et al. 1998) indicated a significant improvement $(p<0.0001)$ in favour of CSI, but by the midterm follow-up (6 months), the effect was no longer significant $(p=0.84)$. Contradictory results were found in the two articles that measured shoulder ROM (Hay et al. 2003; van der Windt et al. 1998). From these results, we can conclude that apart from a significant improvement in shoulder function in favour of CSI at the short-term followup (6-7 weeks), no evidence was found for the superiority of CSIs compared with physiotherapy in the short term, mid-term and long term. 
TABLE 7: Results (mean and 95\% confidence interval) for the measurement of shoulder function in Rhon et al. (2014).

\begin{tabular}{|c|c|c|c|c|}
\hline GRC score $(-7$ to +7$)$ & CSI mean $(95 \% \mathrm{CI})$ & Physiotherapy mean $(95 \% \mathrm{Cl})$ & Mean difference $(95 \% \mathrm{Cl})$ & $p$-value of mean difference \\
\hline 1 month & $3(2$ to 5$)$ & $3(2$ to 5$)$ & $0(-2$ to 2$)$ & 0.99 \\
\hline 3 months & 3 (2 to 4$)$ & 4 (3 to 5 ) & $1(-2$ to 1$)$ & 0.32 \\
\hline 6 months & 3 (2 to 4$)$ & 3 (1 to 4$)$ & $0(-1$ to 2$)$ & 0.32 \\
\hline 1 year & 3 (2 to 4$)$ & 3 (2 to 4$)$ & $0(-2$ to 1$)$ & 0.53 \\
\hline
\end{tabular}

Source: Authors' own work

$\mathrm{Cl}$, confidence interval; $\mathrm{CSI}$, Corticosteroid injections; GRC, global rating of change.

\begin{tabular}{|c|c|c|c|c|c|c|c|c|c|c|c|c|}
\hline \multirow[b]{2}{*}{ Study or Subgroup } & \multicolumn{3}{|c|}{ CSI } & \multicolumn{3}{|c|}{ Physiotherapy } & \multirow[b]{2}{*}{ Weight } & \multirow{2}{*}{$\begin{array}{l}\text { Std. Mean Difference } \\
\text { IV, Fixed, } 95 \% \mathrm{Cl}\end{array}$} & \multirow{2}{*}{\multicolumn{3}{|c|}{$\begin{array}{l}\text { Std. Mean Difference } \\
\text { IV, Fixed, } 95 \% \text { Cl }\end{array}$}} & \\
\hline & Mean & SD & Total & Mean & SD & Total & & & & & & \\
\hline Hay et al. 2003 & 3.03 & 6.3 & 88 & 2.56 & 5.4 & 95 & $65.3 \%$ & $0.08(-0.21,0.37)$ & & \multirow[t]{2}{*}{ - } & \\
\hline Rhon et al. 2014 & 0 & 0 & 0 & 0 & 0 & 0 & & Not estimable & & & & \\
\hline van der Windt et al. 1998 & 39 & 27 & 52 & 14 & 27 & 56 & $34.7 \%$ & $0.92(0.52,1.32)$ & & \multicolumn{2}{|c|}{-} & \\
\hline Total $(95 \% \mathrm{Cl})$ & & & 140 & & & 151 & $100.0 \%$ & $0.37(0.14,0.61)$ & & & & \\
\hline \multicolumn{8}{|c|}{ Test for overall effect: $Z=3.11(P=0.002)$} & -4 & $\begin{array}{c}-2 \\
\text { Favours Physio }\end{array}$ & 0 & $\begin{array}{c}1 \\
2 \\
\text { Favours CSI }\end{array}$ & 4 \\
\hline
\end{tabular}

Source: Authors' own work. Compiled with Revman@ Review Manager Software.

FIGURE 2: Results for the combined effect for shoulder function at 6-7 weeks.

\begin{tabular}{|c|c|c|c|c|c|c|c|c|c|c|c|}
\hline \multirow{3}{*}{$\begin{array}{l}\text { Study or Subgroup } \\
\text { Hay et al. } 2003\end{array}$} & \multicolumn{3}{|c|}{$\mathrm{CSI}$} & \multicolumn{3}{|c|}{ Physiotherapy } & \multirow[b]{2}{*}{ Weight } & Std. Mean Difference & \multirow{2}{*}{\multicolumn{2}{|c|}{$\begin{array}{l}\text { Std. Mean Difference } \\
\text { IV, Fixed, } 95 \% \mathrm{Cl}\end{array}$}} & \\
\hline & Mean & SD & Total & Mean & SD & Total & & IV, Fixed, $95 \% \mathrm{Cl}$ & & & \\
\hline & 4.55 & 5.9 & 87 & 5.97 & 5.4 & 94 & $63.5 \%$ & $-0.25(-0.54,0.04)$ & -1 & \multirow{4}{*}{$5-$} & \\
\hline Rhon et al. 2014 & 0 & 0 & 0 & 0 & 0 & 0 & & Not estimable & & & \\
\hline van der Windt et al. 1998 & 45 & 30 & 51 & 33 & 34 & 54 & $36.5 \%$ & $0.37(-0.02,0.76)$ & & & \\
\hline Total $(95 \% \mathrm{Cl})$ & & & 138 & & & 148 & $100.0 \%$ & $-0.02(-0.26,0.21)$ & & & \\
\hline \multicolumn{8}{|c|}{ Test for overall effect: $Z=0.20(P=0.84)$} & -4 & $\begin{array}{c}-2 \\
\text { Favours Physio }\end{array}$ & $\begin{array}{c}2 \\
\text { Favours CSI }\end{array}$ & 4 \\
\hline
\end{tabular}

Source: Authors' own work. Compiled with Revman@ Review Manager Software.

FIGURE 3: Results for the combined effect for shoulder function at 26 weeks ( 6 months).

The article by van der Windt et al. (1998) was the only one that showed a significant decrease in day and night pain in the short term and long term; shoulder external ROM in the short term and mid-term as well as shoulder function in the short term and mid-term in favour of the CSI group. Van der Windt et al. (1998) came to the conclusion that the short-term differences found between the CSIs and physiotherapy groups mainly resulted from the fast relief of symptoms participants in the CSIs group experienced owing to the antiinflammatory and analgesic properties of CSIs. Celik et al. (2009) compared CSIs and physiotherapy with physiotherapy alone in the treatment of SIS and the purpose of the study was to determine whether or not CSIs played a beneficial role in the management of SIS. At the initial 24-hour follow-up, the CSIs group had a greater reduction in pain scores. At the 3- and 6- week re-evaluation, both groups showed a significant improvement in pain, function, ROM and strength compared with their pre-treatment scores and betweengroup analyses indicated no significant difference. A RCT conducted by Crawshaw et al. (2010) compared CSI and exercise with exercise therapy alone in patients with moderate to severe shoulder pain. They found significantly earlier improvements in pain and functional disability at 1 and 6 weeks in the group given CSI combined with exercise therapy but found no significant difference in the score on the shoulder pain and disability index at 3 months. Crawshaw et al. (2010) suggested that if early pain relief is a priority for the patient and physiotherapist, adding local CSI to a course of physiotherapy would seem to be the best management option. The initially significant short-term effect of shoulder function at 6-7 weeks (see Table 8) in favour of CSI in the current study was most likely owing to the anti-inflammatory and analgesic properties of CSIs.

A RCT by Dickens, Williams \& Bhamra (2005) included two groups with SIS, one receiving physiotherapy and another continuing with daily activities; however, both groups had received a minimum of three CSIs $(80 \mathrm{mg}$ of methylprednisolone acetate) prior to the commencement of the trial. At the 6-month follow-up, the results showed that physiotherapy significantly decreased shoulder pain and increased shoulder strength and function over and above the use of CSIs. CSIs and physiotherapy seem to work in synergy, the former decreases inflammation and pain, while physiotherapy addresses the mechanical problems that may have caused SIS. Dickens et al. (2005) found that the combination of CSIs and physiotherapy could be significantly superior to CSIs alone, in improving SIS symptoms to such an extent that the patients in their study no longer require surgery. The potential benefit and detrimental effects of CSI should however be considered before CSIs are administered to patients with SIS. Maman et al. (2015) cautioned that the biological basis of the effect of CSIs is still not understood and that optimal dosages, delivery techniques and intervals between injections and post-injection care remain unknown. Their animal study found that a triple methylprednisolone 
acetate injection significantly weakened the rotator cuff muscles and had a detrimental effect on bone quality in rats (Maman et al. 2015). Despite the popularity of CSIs, there is a serious lack of scientific research on the short- and long-term side-effects of CSIs in humans with SIS, and improvement after a CSI may not necessarily be contributed to a decreased progression of SIS. This was demonstrated by Ramírez et al. (2014) who found a $17 \%$ increase of full-thickness rotator cuff tears 12 weeks after a single CSI (triamcinolone acetate 40 $\mathrm{mg}$ ), even though patients reported significant improvement in pain symptoms ( $p=0.0001$; VAS score) and shoulder ROM ( $p=0.002$ for forward elevation and external rotation). After an extensive literature search, no evidence on the mid- and long-term effect of CSIs on disease progression in patients with SIS could be found. The use of CSIs to ease initial pain and improve function in patients with SIS should thus be carefully considered.

The strengths of this review are that a systematic search strategy was conducted utilising seven scientific databases. Each step of the review was completed independently by at least two investigators and cross-checked by seven of the eight investigators. In addition, an effort was made to contact the authors of the included articles to acquire point measures and measures of variability, which enabled us to conduct a more thorough analysis and combine and pool data for shoulder function. The three RCTs that qualified for this systematic review were classified as evidence Level II according to the NHMRC and were all of high methodological quality, scoring an average of 7.3/10 on the PEDro scale. Blinding of the therapists and participants in the included articles was not possible owing to the nature of the interventions used. A limitation of the study by van der Windt et al. (1998) was that they did not attempt to blind the assessors, which could have led to bias during the evaluation of the different outcomes.

In keeping with the findings of this review, no strong evidence supports the recommendation in favour of CSIs over physiotherapy for the treatment of loss of function, decreased ROM and pain in SIS. The recommended choice of intervention for patients with SIS should therefore take into account the patient (e.g. aversion to injections) and physiotherapist's preferences as well as the availability of the treatment options (e.g. medical doctors trained in giving CSIs for SIS). It is important to involve the patient in the decisionmaking process and clearly establish the expectations and preferences of the patient. Since sufficient evidence-based information regarding long-term effects of CSI on the progression SIS is seriously lacking, the use of CSIs to ease initial pain and improve function should be carefully considered and physiotherapy management of SIS thus serve as an effective low-risk option.

\section{Conclusion}

In summary, there is Level II evidence suggesting that besides a significant improvement in shoulder function in favour of CSIs at 6-7 weeks' follow-up, no evidence was found for the superiority of CSIs compared with physiotherapy for pain and ROM in the short term. The medium- and long-term outcomes for pain, ROM and shoulder function do not favour the use of CSIs over physiotherapy. The management for patients with SIS should therefore take into account the patient and physiotherapist's preferences as well as the possible long-term beneficial and adverse effects of CSIs on the progression of SIS.

\section{Acknowledgements Competing interests}

The authors declare that they have no financial or personal relationships which may have inappropriately influenced them in writing this article.

\section{Authors' contributions}

M.B. was the project leader and responsible for the conception and design of the study, revising the manuscript critically for important intellectual content and approving the final version to be published. All the authors were responsible for searching the databases. C.A., K.D. and A.N. were responsible for reviewing and scoring the included papers. N.M. was responsible for extracting and capturing data on a Microsoft Excel spreadsheet and the data was cross-checked by the rest of the seven research team members (C.P., A.G., A.S., C.A., K.D., A.N. and M.B.).

\section{References}

Akgün, K., Birtane, M. \& Akarırmak, Ü., 2004, 'Is local subacromial corticosteroid injection beneficial in subacromial impingement syndrome?', Clinical Rheumatology 23, 496-500. http://dx.doi.org/10.1007/s10067-004-0930-7

Celik, D., Atalar, A.C., Guclu, A. \& Demirhan, M., 2009, 'The contribution of subacromial injection to the conservative treatment of impingement syndrome', Acta Orthopaedica et Traumatologica Turcica 43, 331-335. http://dx.doi.org/10.3944/AOTT.2009.331

Crawshaw, D.P., Helliwell, P.S., Hensor, E., Hay, E.M., Aldous, S.J. \& Conaghan, P.G., 2010, 'Exercise therapy after corticosteroid injection for moderate to severe shoulder pain: Large pragmatic randomised trial', British Medical Journal 340, c3037. http://dx.doi.org/10.1136/bmj.c3037

Cummins, C.A., Sasso, L.M. \& Nicholson, D., 2009, 'Impingement syndrome: Temporal outcomes of nonoperative treatment', Journal of Shoulder and Elbow Surgery 18, 172-177. http://dx.doi.org/10.1016/j.jse.2008.09.005

de Morton, N.A., 2009, 'The PEDro scale is a valid measure of the methodological quality of clinical trials: A demographic study', Australian Journal of Physiotherapy 55, 129-133. http://dx.doi.org/10.1016/S0004-9514(09)70043-1

Dickens, V.A., Williams, J.L. \& Bhamra, M.S., 2005, 'Role of physiotherapy in the treatment of subacromial impingement syndrome: A prospective study', Physiotherapy 91, 159-164. http://dx.doi.org/10.1016/j.physio.2004.10.008

Dorrestijn, O., Stevens, M., Winters, J.C., van der Meer, K. \& Diercks, R.L., 2009 'Conservative or surgical treatment for subacromial impingement syndrome? A systematic review', Journal of Shoulder and Elbow Surgery 18, 652-660. http:// dx.doi.org/10.1016/j.jse.2009.01.010

Gruson, K., Ruchelsman, D. \& Zuckerman, J., 2008, 'Subacromial corticosteroid injections', Journal of Shoulder and Elbow Surgery 17, 118-130. http://dx.doi. org/10.1016/j.jse.2007.07.009

Hanratty, C.E., McVeigh, J.G., Kerr, D.P., Basford, J.R., Finch, M.B., Pendleton, A. et al., 2012 , 'The effectiveness of physiotherapy exercises in subacromial impingement syndrome: A systematic review and meta-analysis', Seminars in Arthritis and Rheumatism 42, 297-316. http://dx.doi.org/10.1016/j.semarthrit.2012.03.015

Harrison, A.K. \& Flatow, E.L., 2011, 'Subacromial impingement syndrome', Journal of American Academy of Orthopaedic Surgeons 19, 701-708. http://dx.doi. org/10.5435/00124635-201111000-00006

Hay, E.M., Thomas, E., Paterson, S.M., Dziedzic, K. \& Croft, P.R., 2003, 'A pragmatic randomised control trial of local corticosteroid injection and physiotherapy for the treatment of new episodes of unilateral shoulder pain in primary care', Annals of the Rheumatic Diseases 62, 394-399. http://dx.doi.org/10.1136/ard.62.5.394

Maman, E., Yehuda, C., Pritsch, T., Morag, G., Brosh, T., Sharfman, Z. et al., 2015, 'Detrimental effect of repeated and single subacromial corticosteroid injections on the intact and injured rotator cuff: A biomechanical and imaging study in rats', The American Journa of Sports Medicine 44(1), 177-182. http://dx.doi.org/10.1177/0363546515591266 
Merlin, T., Weston, A. \& Tooher, R., 2009, 'Extending an evidence hierarchy to include topics other than treatment: Revising the Australian "levels of include topics other than treatment: Revising the Australian "levels of ovidence", $B M C$ Medical

Michener, L.A., McClure, P.W. \& Karduna, A.R., 2003, 'Anatomical and biomechanical mechanisms of subacromial impingement syndrome', Clinical Biomechanics 18 369-379. http://dx.doi.org/10.1016/S0268-0033(03)00047-0

Michener, L.A., Walsworth, M.K. \& Burnet, E.N., 2004, 'Effectiveness of rehabilitation for patients with subacromial impingement syndrome: A systematic review', Journal of Hand Therapy 17, 152-164. http://dx.doi.org/10.1197/j.jht.2004. 02.004

NHMRC additional levels of evidence and grades for recommendations for developers of guidelines. Canberra: NHMRC. 2005. Viewed 1 September 2016, from http:// www.nhmrc.gov.au/_files_nhmrc/file/guidelines/stage_2_consultation_levels and grades.pdf

Petty, N.J., 2011, Neuromusculoskeletal examination and assessment: A handbook for therapists, 4th edn., Elsevier, United Kingdom, p. 265

Ramírez, J., Pomés, I., Cabrera, S., Pomés, J., Sanmartí, R. \& Cañete, J.D., 2014 'Incidence of full-thickness rotator cuff tear after subacromial corticosteroid injection: A 12-week prospective study', Modern Rheumatology 24, 667-670. http://dx.doi.org/10.3109/14397595.2013.857798
RevMan, 2008, 'IMS Cochrane', viewed 24 January 2015, from http://ims.cochrane. org/revman

Rhon, D.I., Boyles, R.B. \& Cleland, J.A., 2014, 'A pragmatic randomized trial, oneyear outcome of subacromial corticosteroid injection compared with manual physical therapy for the management of unilateral shoulder impingement syndrome', Annual Internal Medicine 161, 161-169. http://dx.doi.org/10.7326/ M13-2199

Ried, K., 2006, 'Interpreting and understanding meta-analysis graphs: A practical guide', Australian Family Physician 35, 635-638.

Umer, M., Qadir, I. \& Azam, M., 2012, 'Subacromial impingement syndrome', Orthopaedic Reviews (Pavia) 4(2), viewed 7 October 2014, from http://www.ncbi. nlm.nih.gov/pmc/articles/PMC3395987/\#

van Der Sande, R., Rinkel, W.D., Gebremariam, L., Hay, E.M., Koes, B.W. \& Huisstede, B.M., 2013, 'Subacromial impingement syndrome: Effectiveness of pharmaceutical interventions-nonsteroidal anti-inflammatory drugs, corticosteroid, or other injections: A systematic review', Archives of Physical Medicine and Rehabilitation 94, 961-976. http://dx.doi.org/10.1016/j.apmr.2012.11.041

van der Windt, D.A., Koes, B.W., Deville, W., Boeke, A.J., de Jong, B.A. \& Bouter, L.M., 1998, 'Effectiveness of corticosteroid injections versus physiotherapy for treatment of painful stiff shoulder in primary care: Randomised trial', British Medical Journal 317, 1292-1296. http://dx.doi.org/10.1136/bmj.317.7168.1292 